\title{
Determinants of Choice for Dining out to Fast Food and Traditional Food
}

\author{
Abdul Samad Shaikh \\ Dr. Mustaghis-Ur-Rehman
}

\begin{abstract}
Expenditure on food-away-from-home has been increasing with a rapid increase in market share of fast food industry. In this paper, food-away-from-home has been analyzed in the context of two different types of restaurants i.e. fast food and traditional food restaurants. The trend in the fast food may impact the structure of the food distribution and demand for goods at farm level. This study investigates the effects of selected socio-demographic variables on consumers' choice for fast food and traditional food restaurants. The variables considered in this study were age, income, gender, taste, cost and quality of customer service. These variables were used to check whether and to what extent they affect consumers' choice to dine out to either fast food or traditional food restaurants. Gender and quality of customer service found to be insignificant for fast food restaurants, while significant for traditional food restaurants. All other variables were found significant for both types of restaurants.
\end{abstract}

Keywords: Food-away-from-home, fast food, traditional food.

\section{Introduction}

\subsection{Background of the Study}

The share of fast food expenditure has been increasing not only in Pakistan but all around the world. Fast food has social and biological drawbacks. Fast food is increasingly becoming popular which is leading to decrease in share of traditional food which have hundreds of years of historical background. Traditional food is the part of Pakistani culture. Increase in the supply of fast food restaurants causes increase in obesity and obesity related diseases (Dunn, 2008).

This study not only draws attention to socio-cultural impacts of fast food diet but also tries to suggest ways how restaurants can improve their promotional strategies. Also this study draws the attention of government decision makers towards problems and opportunities associated with fast food and traditional food restaurants.

\subsection{Problem Statement}

Eating-out habits are now-a-days taking momentum in our society. Fast food and traditional food restaurants are two options for out-eaters. As market of out eating is expanding, it seems important to explore the customer preferences for either of two for developing deep understanding of future prospects of the two types of business.

\subsection{Objectives of the study}

To investigate the relationship between two types of customers' preferences (i.e. preference for fast food or traditional food) with reference to age, gender, income, taste, cost, and quality of customer services.

\subsubsection{Macro Objectives}

Macro objective of this research is to investigate customers' preferences for dining-out to traditional vs. fast food restaurants in terms of age, gender, income, taste, cost, and quality of customer services.

Abdul Samad Shaikh is an MS student at SZABIST, Karachi, a_samad1112003@yahoo.com Dr. Mustaghis-Ur-Rehman is Associate Professor at SZABIST, Karachi, mustaghis@szabist.edu.pk

\subsubsection{Micro Objectives}


$>$ To investigate consumers' criteria for choosing between fast food and traditional food for dining out.

$>$ To explore future prospects of eating-out industry.

\subsection{Research Methodology}

This research is both qualitative and quantitative in nature. Closed ended and open ended questionnaires will be used for primary data collection. For secondary data books, magazines, journals, and internet will be searched.

\subsubsection{Nature of Study}

Customer preferences for dining out at fast food restaurants have not yet been explored in case of Karachi. Therefore the nature of research is exploratory.

\subsubsection{Data Collection}

Primary data will be collected using closed-ended and open ended questionnaire. Sources of secondary data are books, newspapers, magazines, research articles and internet.

\subsubsection{Sampling and Sampling Technique}

Due to absence of sample frame of population, a non-probability sampling methodology has been used. Students of management science have been contacted as sampling units for data collection. For this purpose, top four institutes of Karachi have been selected based on the ranking of Higher Education Commission (HEC). These four institutes were Institute of Business Administration (IBA), Shaheed Zulfikar Ali Bhutto Institute of Science and Technology (SZABIST), Iqra University and Institute of Business Management (loBM).

A total of 120 questionnaires were distributed. The response rate was $83 \%$. Quota sampling method has been used amongst selected institutes. The details of students enrolled and selected sample size from each institute is as follows.

\begin{tabular}{|l|l|l|}
\hline Name of Institution & Number of students enrolled & Sample size \\
\hline IBA & 1350 & 26 \\
\hline SZABIST & 1550 & 30 \\
\hline IQRA University & 1600 & 31 \\
\hline IoMB & 1750 & 33 \\
\hline Total & 6250 & 120 \\
\hline
\end{tabular}

Table-1 Sampling distribution

\subsubsection{Key variables}

Key variables which are expected to be significant determinants of customer choice for dining-out to traditional vs. fast food restaurants are as follows:

- Age

- Income

- Gender

- Taste

- Quality of customer services

- Cost

\subsection{Scope of the study}


This study considers only one dimension of consumer behavior for dining out i.e. preferences of choice for fast food and traditional food.

\subsubsection{Thematic Focus}

Because of vague concept and definition of fast food, the researcher considers fast food chains as providing fast food in Karachi.

\subsubsection{Geographic Focus}

The primary data will only be collected from Karachi. Therefore the geographic scope of this study is limited to Karachi.

\subsection{Limitations of the study}

Main constraints of the study will be time limitation which is about three months for such a study. Besides, data collection will be on small scale as it will not be possible to interview out-eaters in the whole Karachi as out-eating is a big industry.

\subsection{Importance of the Study}

Determination of customer preferences for choice between fast food restaurants and traditional food restaurants will lead to refining of promotional strategies of both fast food and traditional food restaurants. A change in market share of fast food and full service restaurants may reflect important changes in what people are eating away from home, because fast food tends to have larger fat and calories than meals prepared at full service restaurants.

\section{Literature Review}

There are many types of foodservice firms including full-service restaurants (traditional food restaurants), fast food restaurants, hotels, and retail stores, compete for consumer's away-from-home expenditure. However full-service (traditional food restaurants) and fast food restaurants have captured bulk of market share. In this study, restaurant industry is considered to be comprised of two categories i.e. full service (traditional food) restaurants and fast food restaurants. Full-service (traditional food) restaurants are defined as establishments with wait staff, tend to offer more varied menus and dining amenities. Fast food establishments tend to emphasize convenience. Consumer expenditure on traditional food (full service) restaurants and fast food restaurants are expected to grow over time. However, the larger increase will likely occur at traditional food (full service) restaurants (McCarcken and Brandt, 1987). McCarcken and Brandt have also shown the importance of various socio-demographic factors by type of eating-out restaurant. These factors are household income, the value of household time, household size and composition, race and age.

Bryne, Capps, and Saha (1998) are of the view that trends away from full service restaurants to fast food restaurants may impact food distribution system, nutritional intake of households and demand of goods at farm level. The remainder of this research is focused on the impact of socio-demographic factors that affect food-away-from-home with respect to the type of restaurant i.e. full-service and fast food restaurants. Bryne, Capps, and Saha (1998) describe FAFH consumption to be characterized as three stage process. First, the decision is made whether to consume FAFH. Second, the decision is made as to which type of restaurant to dine out. Finally, the third stage refers to expenditure level or consumption level decision. This study only brings light to the second stage of their thought.

The FAFH market is most appropriately analyzed within the theoretical framework of household production theory of economics. This theory incorporates less restrictive assumption on models of consumer behavior (McCarcken and Brandt, 1987). The decision to dine-out at a particular type of restaurant is influenced by time and budget constraints. Household production theory considers the role of time in the decision process by incorporating the opportunity cost of time into utility maximization process (Becker 1965). Time is divided into three uses; market work time, household production time, and leisure time. This constraint suggest that time can be converted into market goods and services by using less time in producing commodities in home and more time at market work. Dining at full service restaurant is typically more expensive in both time and money than at quick service restaurants. However, dining at full-service restaurant is often a leisure activity along with food consumption (McCarcken and Brandt, 1987). On the other hand, dining at quick service restaurant is often a time saving activity, since it provides significant time saving relative to home meal preparation and dining at full service restaurants (Kara 1995).

Nickols and Fox (1983) investigated factors affecting number of meals consumed at quick service restaurants, school cafeterias, and full service restaurant. They found 
that family income, household's occupation, and age of the youngest child positively affect the number of meals at fullservice restaurants while these factors did not affect number of meals at quick-service restaurants. They also found a positive relationship between number of meals consumed at quick-service restaurants and a wife's labor force participation. However, wife's labor force participation did not affect the number of meals at full-service restaurants. These results suggest that meals at quick service restaurants are time saving strategy for families with wives employed outside of the home.

Bryne, Capps, and Saha (1998) used regression analysis to examine expenditure by type of foodservice facility. They found that household income, household manager's labor hours, and education of household head had a negative effect on meal expenditure at quick-service facilities while household income had a positive impact on meal expenditure at fullservice restaurants.

Kim (1995) analyzed the impact of household characteristics on expenditure by eating occasion and market segment. Characteristics found to be important in this study include the household's income, time constraints faced by the household manager, the household manager's age, number of people in the household, education level of the household manager, the household's region of residence, and the household's race and ethnicity. A household's demand for food away from home may also depend on the ages of its members. One reason is that tastes may change as people age. For example, if the sensitivity of taste buds diminishes with age, older people may demand foods with bolder flavors (Friddle et al., 2001). Also, older and younger people may have different opportunities to socialize, so if they eat out for different reasons, they may logically go to different kinds of establishments. On balance, empirical studies find that households with younger members tend to spend more money on fast food, while households with older people tend to spend more money on full-service dining (Byrne et al., 1998).

According to Kivela (1999), ambiance factors seem to be the important determining choice variable for 25-34 year old. Auty (1992), Bitner (1992), and Finkelstein (1989) suggest this might be because these groups tend to look for ambiance or atmosphere type restaurants because they provide more suitable social environment for 25-34 year old. The choice determinant variable for 45-54 year old are quality of food, ambiance factors, comfort level, prestige and prompt handling of complaints. Also middle and high income groups have chosen comfort level as their choice determinant variable (Kivela, 1999).

One of the very widely accepted definitions of fast food is that it is the type of meal that is often pre-prepared and served quickly. Fast foods usually have high fat and low nutrition values. Fast foods are convenience foods that can be prepared and served in lesser time and they are usually perceived as inexpensive foods.

Pakistan is a country of more than 150 million consumers. It is world's ninth largest country. Restaurant industry in Pakistan is growing with fast pace. New restaurants are being opened day by day in spite of economic downfall in 2009. This is the industry which significantly contributes to GDP of Pakistan. Although per capita income in Pakistan is not high but an average Pakistani spends $42 \%$ of his income on food (GAIN Report, 2000).

The Western style fast food is becoming increasingly popular in Pakistan. Most of the fast food franchises were established between 1995 and 1999. Most of the franchise restaurants rely on direct import from their regional outlets in Asia and Middle East for a number of input items. Most of the fast food chains exist in urban areas of Pakistan, including Karachi, Lahore, and Islamabad. Some of the fast food chain restaurants which are successfully operating in Pakistan are KFC, Pizza Hut, McDonald's, and Mr. Burger.

\section{Data presentation and Analysis}

Primary data has been collected using closed ended and open ended questionnaire. Questionnaires were distributed to students of management science therefore respondents were of certain age group. The universe of population in this study consisted of four institutes based on the HEC's ranking. These four institutes have a population of more than 8000.These were IBA, SZABIST, IQRA University, and IoBM. But the target population was only the students of management sciences. Six of our target population was 6250. Sample size in this study has been 120. Quota sampling technique was applied to each of the institute to select ultimate samples. Response rate was $83 \%$. And a hundred questionnaires were considered for analysis. Some of the data have been analyzed using Chi square test if independence and remaining analyses were done using descriptive statistics.

Questions about frequency of dining-out were asked and responses were cross-tabulated with other variables to generate results. Respondents were asked that to what extent they agree with the statement that fast food restaurants save time as compare to traditional food restaurants. Responses are shown in the following table:

\begin{tabular}{|c|c|}
\hline Response & Frequency \\
\hline Strongly agree & 16 \\
\hline
\end{tabular}




\begin{tabular}{|c|c|}
\hline Agree & 55 \\
\hline Neutral & 12 \\
\hline Disagree & 14 \\
\hline Strongly disagree & 3 \\
\hline Total & 100 \\
\hline
\end{tabular}

\section{Table 2}

More than $70 \%$ of the respondents are of the view that fast food restaurants save time as compare to traditional food restaurants. This may be one of the reasons of their dining out to fast food restaurants. Only a little more than $15 \%$ are of the view that fast food restaurants do not save time. This seems to be a significant determinant of customers' dining out to fast food restaurants.

Respondents were asked that to what extant they agree with the statement that fast food saves cost as compare to traditional food. Table 3 shows responses of respondents.

\begin{tabular}{|c|c|}
\hline Response & Frequency \\
\hline Strongly agree & 6 \\
\hline Agree & 39 \\
\hline Neutral & 17 \\
\hline Disagree & 30 \\
\hline Strongly disagree & 8 \\
\hline Total & 100 \\
\hline
\end{tabular}

Table 3

Only a little more then $30 \%$ of the respondents are of the view that fast food does not save cost, while more than $39 \%$ of respondents agreed with this statement. Majority of the people are of the view that cost affects their dining-out decision. That is why cost seems to be a significant determinant for dining out decision.

A question was asked to measure to what extent the respondent agrees with the statement that fast food is tastier then traditional food. Table 4 contains the details about answers of respondents.

\begin{tabular}{|c|c|}
\hline Response & Frequency \\
\hline Strongly agree & 16 \\
\hline Agree & 37 \\
\hline Neutral & 20 \\
\hline Disagree & 21 \\
\hline Strongly disagree & 6 \\
\hline Total & 100 \\
\hline
\end{tabular}

Table 4

More the $50 \%$ of the respondents agreed that fast food is tastier than traditional food. While slightly more than $25 \%$ disagreed. That is why taste seems to be significant factor affecting customers' decision to choose between fast food and traditional food restaurants.

Respondents were asked to rate their level of satisfaction with respect to quality of customer services offered by fast food restaurants. Table 11 shows cross-tabulation of frequency of visiting fast food restaurant and quality of customer services offered by fast food restaurants. Results are discussed below:

Table 5 Frequency of visiting fast food restaurant and quality of customer services offered by fast food restaurants

\begin{tabular}{|c|c|c|c|c|c|}
\hline \multicolumn{2}{|c|}{} & \multicolumn{2}{|c|}{$\begin{array}{c}\text { Quality of customer services } \\
\text { offered by fast food } \\
\text { restaurants }\end{array}$} & Total \\
\cline { 2 - 6 } & \multicolumn{2}{|c|}{ high } & average & low & \\
\hline $\begin{array}{c}\text { Frequency of } \\
\text { visiting fast food } \\
\text { restaurant in a } \\
\text { month }\end{array}$ & $\begin{array}{c}\text { Less } \\
\text { than } \\
\text { three }\end{array}$ & 34 & 12 & 13 & 59 \\
\cline { 2 - 6 } & $3-4$ & 9 & 6 & 7 & 22 \\
\cline { 2 - 6 } & $\begin{array}{c}\text { More } \\
\text { than 5 }\end{array}$ & 6 & 7 & 6 & 19 \\
\hline
\end{tabular}




\begin{tabular}{l|l|l|l|l|l|} 
Total & & 49 & 25 & 26 & 100
\end{tabular}

Null hypothesis:

Ho1: frequency of visiting fast food restaurant is independent of quality of customer services offered by fast food restaurants.

Chi square calculated $=4.862$

Critical value $\quad=9.488$

Calculated value does not fall in critical region. Null hypothesis (of independence) is not rejected. Frequency of visiting fast food restaurant is independent of customer service quality offered by fast food restaurants. The test results show that one's preference for quality of customer services has no bearing on one's frequency of visiting fast food restaurant. It means that no particular preference for the fast food could be attached to one's preference for quality of customer services. In this case, customer service quality is not a significant determinant of one's preference for fast food.

Respondents were asked about their age group. Table 6 shows cross-tabulation of age group and frequency of visiting fast food restaurant. It shows that dining out for fast food is more common in younger generation. Those who frequently dine out for fast food belongs more to the younger age group (16-25 years). The frequency of visiting fast food restaurant is almost insignificant in higher age group then lower age group. It shows that customer preferences for fast food are affected by age. Hence it can be inferred that age is a significant determinant of customers' preferences for fast food.

\begin{tabular}{|c|c|c|c|c|}
\hline \multicolumn{2}{|c|}{} & \multicolumn{2}{c|}{ Age (years) } & Total \\
\cline { 3 - 5 } & $16-25$ & $26-35$ & \\
\hline $\begin{array}{c}\text { Frequency of } \\
\text { visiting fast } \\
\text { food } \\
\text { restaurant in a } \\
\text { month }\end{array}$ & $\begin{array}{c}\text { Less } \\
\text { than 3 }\end{array}$ & 39 & 20 & 59 \\
\cline { 2 - 5 } & $\begin{array}{c}\text { More } \\
\text { than 5 }\end{array}$ & 14 & 8 & 22 \\
\hline Total & & 67 & 33 & 100 \\
\hline
\end{tabular}

Table 6 Age and frequency of visiting fast food restaurant

Age has also been cross-tabulated with frequency of visiting traditional food restaurants. The results are contained in table 7 . The results show that dining out for traditional food is more common in younger generation as compare to older age group. The reason may be that younger generation dine-out more frequently to both fast food and traditional food restaurants. But the gap for visits between the two age groups is less prominent in traditional food than for fast food. It shows that people from older age group or mature age group still prefer traditional food over fast food.

\begin{tabular}{|c|c|c|c|c|}
\hline \multicolumn{2}{|c|}{} & \multicolumn{2}{|c|}{ Age(years) } & Total \\
\cline { 3 - 5 } \multicolumn{2}{|c|}{} & $16-25$ & $26-35$ & \\
\hline $\begin{array}{c}\text {.Frequency of } \\
\text { visiting traditional } \\
\text { food in a month }\end{array}$ & Less than 3 & 27 & 21 & 48 \\
\cline { 2 - 5 } & $3-4$ & 21 & 7 & 28 \\
\hline Total & More than 5 & 19 & 4 & 25 \\
\hline
\end{tabular}

Table 7 Age and frequency of visiting traditional food restaurant

Respondents were asked about their income group. Table 8 shows the cross-tabulation of income and frequency of 
visiting fast food restaurant. Results are discussed as under:

\begin{tabular}{|c|c|c|c|c|c|}
\hline \multicolumn{2}{|c|}{} & \multicolumn{3}{|c|}{ Income (Rs.) } & Total \\
\cline { 3 - 6 } \multicolumn{2}{|c|}{} & $\begin{array}{c}\text { Less } \\
\text { than } \\
25000\end{array}$ & $\begin{array}{c}25000- \\
35000\end{array}$ & $\begin{array}{c}\text { More } \\
\text { than } \\
35000\end{array}$ & \\
\hline $\begin{array}{c}\text { Frequency } \\
\text { of visiting } \\
\text { fast food } \\
\text { restaurant }\end{array}$ & $\begin{array}{c}\text { Less } \\
\text { than 3 }\end{array}$ & 36 & 8 & 15 & 59 \\
\cline { 2 - 6 } & $3-4$ & 5 & 11 & 6 & 22 \\
\cline { 2 - 6 } & $\begin{array}{c}\text { More } \\
\text { than 5 }\end{array}$ & 8 & 6 & 5 & 19 \\
\hline Total & & 49 & 25 & 26 & 100 \\
\hline
\end{tabular}

Table 8 Frequency of visiting fast food restaurant and Income

Null hypothesis:

Ho3: frequency of visiting fast food restaurant is independent of level of income.

Chi square calculated $=13.962$

Critical value $\quad=9.488$

Calculated value falls in critical region. Null hypothesis (of independence) is rejected. Frequency of visiting fast food restaurant is dependent on level of income. The test results show that one's level of income has bearing on one's frequency of visiting fast food restaurants. It means that preference for the fast food could be attached to one's level of income. Income level, in this case, is a significant determinant of one's preference for fast food. Income has also been cross-tabulated with frequency of visiting traditional food restaurants. Following is the cross-tabulation of income and frequency of visiting traditional food restaurant. Results are discussed as follows:

\begin{tabular}{|c|c|c|c|c|c|}
\hline & \multicolumn{3}{|c|}{ Income (Rs.) } & \multirow[t]{2}{*}{ Total } \\
\hline & & $\begin{array}{c}\text { Less than } \\
25000\end{array}$ & $\begin{array}{c}25000- \\
35000\end{array}$ & $\begin{array}{c}\text { More than } \\
35000\end{array}$ & \\
\hline \multirow{3}{*}{$\begin{array}{c}\text { frequency of } \\
\text { visiting traditional } \\
\text { food restaurant } \\
\text { in a month }\end{array}$} & $\begin{array}{l}\text { Less } \\
\text { than } 3\end{array}$ & 25 & 8 & 15 & 48 \\
\hline & $3-4$ & 16 & 5 & 7 & 28 \\
\hline & $\begin{array}{l}\text { More } \\
\text { than } 5\end{array}$ & 8 & 12 & 4 & 24 \\
\hline Total & & 49 & 25 & 26 & 100 \\
\hline
\end{tabular}

Table 9 Frequency of visiting traditional food restaurant and Income

Null hypothesis:

Ho4: frequency of visiting traditional food restaurant is independent of income

Chi square calculated $=10.903 \quad$ Critical value $\quad=9.488$

Calculated value falls in critical region. Null hypothesis (of independence) is rejected. Frequency of visiting fast food restaurant is dependent on income group. The test results show that one's level of income has bearing on one's frequency of visiting traditional food restaurant. It means that preference for the traditional food could be attached to one's level of income. Income level, in this case, is a significant determinant of one's preference for traditional food. Gender and frequency of dining out has been cross-tabulated with gender. Details are given in Table 10.

Table 10 Gender and frequency of visiting fast food restaurant

\begin{tabular}{|c|c|c|c|c|}
\hline \multicolumn{2}{|c|}{} & \multicolumn{2}{c|}{ GENDER } & Total \\
\hline \multirow{3}{*}{$\begin{array}{c}\text { visits to fast food } \\
\text { restaurants in a } \\
\text { month }\end{array}$} & $\begin{array}{c}\text { Less } \\
\text { then 3 }\end{array}$ & 30 & 29 & 59 \\
\cline { 2 - 5 } & $3-4$ & 15 & 7 & 22 \\
\cline { 2 - 5 } & $\begin{array}{c}\text { More } \\
\text { then 5 }\end{array}$ & 6 & 13 & 19 \\
\hline \multicolumn{2}{|c|}{ Total } & 51 & 49 & 100 \\
\hline
\end{tabular}


Null hypothesis:

Ho5: Frequency of visiting fast food restaurant is independent of gender.

Chi square calculated $=5.467$

Critical value $\quad=5.991$

Calculated value does not fall in critical region. Null hypothesis (of independence) not rejected. Gender is independent of frequency of visiting fast food restaurants. The test results show that one's gender has no influence on one's frequency of visiting fast food restaurant. Hence no particular preference for the fast food could be attached to one's gender. Both male and female are neutral to choosing fast food and we will have to look at other factors which characterize one's preference for fast food. Gender, in this case, is not a significant determinant of one's preference for fast food.

Gender has also been cross-tabulated with frequency of visiting traditional food restaurants. Table 11 shows crosstabulation of gender to frequency of visiting traditional food restaurant.

\begin{tabular}{|c|c|c|c|c|}
\hline \multicolumn{2}{|c|}{} & \multicolumn{2}{|c|}{ GENDER } & Total \\
\hline \multirow{3}{*}{$\begin{array}{c}\text { frequency of visiting } \\
\text { traditional food } \\
\text { restaurant in a } \\
\text { month }\end{array}$} & Less than three & 34 & 14 & 48 \\
\cline { 2 - 5 } & & & & \\
\cline { 2 - 5 } & $3-4$ & 6 & 22 & 28 \\
\cline { 2 - 5 } & More than 5 & 11 & 13 & 24 \\
\hline Total & & 51 & 49 & 100 \\
\hline
\end{tabular}

Table 11 Gender and frequency of visiting traditional food restaurant

Null hypothesis:

Ho6: Frequency of visiting traditional food restaurant is independent of gender.

Chi square calculated $=17.61$

Critical value $\quad=5.991$

Calculated value falls in critical region. Null hypothesis (of independence) is rejected. Frequency of visiting fast food restaurant is dependent on gender. The test results show that one's gender has influence on one's frequency of visiting traditional food restaurant, i.e. preference for the traditional food could be attached to one's gender. Gender, in this case, is a significant determinant of one's preference for traditional food.

The data shows responses of people regarding their cost perception of fast food as compare to traditional food. When asked that fast food is cheaper than traditional food, only $24 \%$ of respondents agreed while $42 \%$ disagreed. This has been the surprising element in this research because generally fast food is considered to be cheaper than traditional food. Therefore cost seems to be a significant determinant of both fast food and traditional food.

\section{Results and Findings}

In spite of a great shift of consumers' habits from traditional food to fast food, average frequency of visiting a traditional food restaurant is still greater than average frequency of visiting fast food restaurant. More than $50 \%$ of people visit traditional food restaurant in a month. Certain variables were tested to check whether they affect consumers' dining-out decision. These variables are age, gender, income, taste, cost and quality of customer services. All respondents were at least 12 years of education. Despite being relatively educated and cognizant with drawbacks of fast food, more than $30 \%$ people visit fast food restaurants more than three times in a moth. One of the reasons for this behavior is the age bracket of respondents in this study. More than $65 \%$ respondents were less than 25 years of age. Because of inclination towards western style of living, young generation visits more frequently to fast food restaurants than traditional food restaurants. They usually do not like to socialize with people and therefore want quick meals. $70 \%$ of the respondents in this study were of the view that fast food saves time. People of less than 25 years of age usually have less purchasing power as compare to older ones. That is why cost of dining-out to fast food restaurants is affected by cost. More than $40 \%$ of the respondents agreed that one of the reasons for selecting fast food is cost. Taste is also found to be a determinant of dining-out decision.

Since fast food dining is cost effective that is why people do not usually focus more on customer service quality. Customer service quality has not been found to be a significant determinant of dining out to fast food restaurant. But it has been found significant for dining out to traditional food 
restaurants. Income has also been found to be a determinant of dining-out decision for both fast food and traditional food restaurants. Gender has not been found significant determinant of dining-out to fast food restaurants, while it has been found significant in case of traditional food dining.

\section{Conclusion and Recommendations}

The relationship between dining-out choices and socio-demographic variables has been investigated. Certain variables have been tested in cross comparison of dining-out to fast food restaurant and traditional food restaurants. On the basis of this research analysis, our findings can be concluded as follows:

\subsection{Conclusion}

The global acceptance of fast food has impacted our society. Fast food is increasingly taking roots in Pakistan. But interestingly traditional fast food is also being popular not only in cities but in rural areas as well. People are increasingly dining out, especially the younger generation is increasingly inclined towards fast food. The idea that why people are increasingly dining out to specially fast food restaurants was so curious that it led the researcher to investigate variables that affects the decision of dining out.

Results suggest that gender is not a determinant of customers' preference for fast food. It means that it does not matter for fast food restaurants whether their customers are male or female. Both male and female did not show significant differences as far as their frequency of dining-out are concerned. Gender has been proved to be a significant determinant of customers' preferences for traditional food. It means that male and female have shown significantly different dining-out frequencies to traditional food restaurants. Quality of customer service is not a determinant of customers' preference for fast food. It is concluded that customers do not give importance to customer service quality in fast food restaurants.

Customer service quality in case of traditional food restaurants significantly affects frequency of dining-out to traditional food restaurants. It is also evident from analysis that income is a significant determinant of customers' preferences to both fast food and traditional food restaurants. Higher income groups tend to dine out to both traditional and fast food restaurant. Cost of dining-out is also a determinant of dining-out for both fast food and traditional food restaurant. Taste is also a determinant of customers' preferences for dining-out to both types of restaurants. The results also show that majority of the respondents were of the view that fast food is tastier than traditional food. The reason for this may be that majority of the respondents were of age group between 16 years to 25 years. It has also been evident by analysis that lower age groups tend to dine-out more frequently to fast food restaurants. Age has also found to be a significant determinant and lower age groups were found to dine-out to traditional food restaurants more frequently than older age group. The analysis shows that lower age groups as a whole dine-out more frequently than higher age groups.

\subsection{Recommendations}

Traditional food restaurants are suggested to focus on customer service quality. They should take measures to train and develop their customer contact employees. By doing so, they can increase the frequency of customers visiting their restaurant. Both fast food and traditional food restaurants are suggested to adopt competitive pricing approaches at least for mass markets or launch new products with lower prices for lower income groups, although lower income group tend to dine-out less frequently but is one of the largest segments of Pakistan. Both types of restaurants are suggested to focus on taste dimension of their product as it is evident that taste is a determinant of customers' preferences for dining-out to both types of restaurants. Greater significance of taste of fast food restaurants suggest that a little improvement in taste can bring relatively large increase in dining-out frequency to fast food restaurants. Fast food restaurants are specifically suggested to focus on lower age groups, and design products with the specific requirements of younger generation. Traditional food restaurants are strongly suggested to spend significant amount of their budget to research and development because fast food industry is engaged in continuously improving taste dimension of their products. 


\section{References}

Auty, S. (1992) "Consumer choice and segmentation in the restaurant industry", The Service Industry Journal, Vol. 12(8).

Bitner, M.j (1992) "Servicescapes: The impact of physical surroundings on customers and employees", Journal of Marketing, pp. 56.

Bowman, S. A. \& Vinyard, B. T. (2004). "Fast food consumers vs. non-fast food consumers: A comparison of their energy intakes, diet quality, and overweight status", Journal of the American College of Nutrition, Vol. 23, pp. 163168.

Byrne, P., O. Capps Jr., and A. Saha.(1998) "Analysis of Quick-server, Mid scale and up scale Food Away From Home Expenditures," The International Food and Agribusiness Management Review, pp. 51-72.

Dunn, Richard (2008) "Obesity and the Availability of Fast-food: an instrumental variables approach", Journal of Mimeo.

Finkelstein, J. (1989). Dining Out: A Sociology of Modern Manners, Polity, Cambridge.

Freisling, H., Elmadfa, I., \& Gall, I. (2006). "The effect of socioeconomic status on dietary intake, physical activity, and body mass index in Austrian pregnant women", Journal of Human Nutrition Diet, Vol. 19, pp. 437-445.

Friddle, C., S. Mangaraj, and J. Kinsey (2001) "The food service industry: Trends and Changing Structure in the new millennium", Working paper \#01-02, the Retail Food Industry Center, University of Minnesota

GAIN Report (2000) 'Pakistan Retail Food Sector Report,' www.fas.usda.gov/GainFiles/200011/60678815.pdf

GAIN Report (1999) 'Pakistan HRI Food Service Sector,' www.fas.usda.gov/GainFiles/200010/40678594.pdf

Kim W.J. (1995) "Factors Affecting Expenditure of Food Away From Home in the Commercial Establishment by Type of Eating Place and Meal Occasion", Hospitality Research Journal, Vol. 19: pp. 15-31.

Kara A., Kaynak, E., and Kuchkemiroglu, O. (1995) "Marketing strategies for fast food restaurants: a customer view. International Journal of Contemporary Hospitality Management, Vol. 7(4), pp. 16-22.

Kivela, J., Reece, J., and Inbakaran, R. (1999) "Consumer research in restaurant environment. Part 2: Research design and analytical methods", International journal of Contemporary Hospitality Management, Vol. 11(6), pp. 119.

Lin, B. H., Guthrie, J., \& Blaylock, J. R. (1996). "The diets of America's children: Influence of dining out, household characteristics and nutrition knowledge". Washington DC: U.S. Department of Agriculture, Economic Research Service.

Molitor, G. T. T. (1990). "Food systems: Perspectives on demographics and affluence, food supply, and consumption. Environmental Health Perspectives", Journal of agricultural economics Vol. 86, pp. 201-223.

Mancino, L., Lin, B. H., \& Ballenger, N. (2004)."The role of economics in eating choices and weight outcomes", Washington, DC: U. S. Department of Agriculture, Economic Research Service, Agricultural Bulletin Number 791

"Away from Home Expenditures", International Food and Agribusiness Management Review, Vol. 1(1).

McCarcken V. and Jon A. Brandt (1987) "Household

Consumption of Food-Away-From-Home: Total 
expenditure and by Type of Food Facility", American Journal of Agricultural Economics, Vol. 69, No. 2.

Nicols S. Y., and Fox K. D. (1983), Buying time and Saving time: Strategies for managing household production" Journal of consumer research, Vol. 10, pp. 197-208.

Patrick J. Byrne, Oral Capps Jr., and Atanu Saha (1998) "Analysis of Quick-service, Mid-scale, and Up-scale Food“

Stewart, H., Blisard, N., Bhuyan, S., \& Nayga, R. M. (2004, January). "The demand for food away from home: Full services or fast food?" Washington, DC: U. S. Department of Agriculture, Economic Research Service, Agricultural Economic Report No. 829. 